\title{
MODEL PEMBELAJARAN ACTIVE KNOWLEDGE SHARING TERHADAP HASIL BELAJAR MATEMATIKA SISWA SMP
}

\section{THE INFLUENCE OF ACTIVE KNOWLEDGE SHARING LEARNING MODEL ON MATHEMATICS LEARNING OUTCOMES OF JUNIOR HIGH SCHOOL STUDENTS}

\author{
Lela Permanasari ${ }^{1 *}$, Kenny Candra Pradana ${ }^{2}$ \\ ${ }^{1}$ Sekolah Tinggi Ilmu Keguruan dan Ilmu Pendidikan - PGRI, Jl. Chairil Anwar, Durian Payung, Kec. \\ Tj. Karang Pusat, Kota Bandar Lampung, Lampung 35214, Indonesia. \\ ${ }^{2}$ Universitas Sang Bumi Ruwa Jurai, Jl. Imam Bonjol No. 486, Langkapura, Bandar Lampung 35118, \\ Indonesia. \\ *Corresponding Author. E-mail: permanalelasari@gmail.com
}

\begin{abstract}
Abstrak
Tujuan dari penelitian ini adalah untuk mengetahui pengaruh model pembelajaran Active Knowledge Sharing terhadap hasil belajar matematika siswa kelas VII Semester Genap SMP Negeri 8 Bandar Lampung. Metode yang digunakan dalam penelitian ini adalah eksperimen dengan tingkat eksplorasi kuantitatif. Populasi penelitian ini adalah seluruh siswa kelas VII SMP Negeri 8 Bandar Lampung. teknik sampling yang digunakan adalah teknik Random Sampling. Sampel penelitian kelas VII K sebanyak 21 orang sebagai kelas eksperimen dan kelas VII G sebanyak 23 orang sebagai kelas kontrol. Adapun teknik pengumpulan data menggunakan tes. Pengujian hipotesis dengan menggunakan rumus statistik t-tes. Dari hasil pengujian hipotesis menggunakan rumus statistik t-tes diperoleh nilai signifikansi 2 arah (t-tailed) 0.000 kurang dari 0.05. Maka dapat disimpulkan rata-rata hasil belajar matematika siswa yang menggunakan model pembelajaran Active Knowledge Sharing lebih tinggi dari siswa yang menggunakan model pembelajaran konvensional. Dengan demikian ada pengaruh model pembelajaran Active Knowledge Sharing terhadap hasil belajar matematika pada siswa kelas VII semester genap SMP Negeri 8 Bandar Lampung.
\end{abstract}

Kata kunci: Active Knowledge Sharing, Hasil Belajar Matematika, Model Pembelajaran, Siswa SMP

\begin{abstract}
The purpose of this study was to determine the effect of the Active Knowledge Sharing learning model on the mathematics learning outcomes of seventh grade students in the Even Semester of SMP Negeri 8 Bandar Lampung. The method used in this study is an experiment with a quantitative exploration level. The population of this study were all seventh grade students of SMP Negeri 8 Bandar Lampung. The sampling technique used is the Random Sampling technique. The research sample for class VII $K$ was 21 people as the experimental class and class VII G as many as 23 people as the control class. The data collection techniques using tests. Hypothesis testing using the statistical formula $t$-test. From the results of hypothesis testing using the statistical formula $t$-test obtained a 2-way ( $t$-tailed) significance value of 0.000 less than 0.05. So it can be concluded that the average mathematics learning outcomes of students who use the Active Knowledge Sharing learning model are higher than students who use conventional learning models. Thus, there is an effect of the Active Knowledge Sharing learning model on the mathematics learning outcomes of the seventh grade students in the even semester of SMP Negeri 8 Bandar Lampung.
\end{abstract}

Keywords: Qur'an Active Knowledge Sharing, Mathematics Learning Outcomes, Learning Models, Junior High School Students 
Ensiklopedia, 01 (01), 2021 - 2

Lela Permanasari, Kenny Candra Pradana

\section{PENDAHULUAN}

pendidikan merupakan salah satu kebutuhan yang sangat penting dan mendasar bagi kehidupan manusia, kelompok masyarakat, atau bangsa (Cahyono, 2015). Bagi kehidupan manusia, pendidikan merupakan kebutuhan manusia mutlak yang harus di penuhi sepanjang hayat (Adelina Yuristia, 2018). Karena dengan adanya pendidikan manusia dapat memperoleh pengetahuan yang lebih baik dan dapat pula tumbuh proses perubahan tingkah laku yang dapat memenuhi kebutuhan dirinya dan sekaligus membawa perubahan bagi pembaharuan bangsa dan negara. Secara singkat, melalui pendidikan upaya peningkatan kesejahteraan rakyat dapat diwujudkan (Sudarsana, 2016).

Masalah pendidikan senantiasa menjadi topik perbincangan yang menarik di kalangan masyarakat luas (Fahmi et al., 2020), terutama di kalangan guru, orang tua, lebih lagi di kalangan pakar pendidikan. Hal ini merupakan sesuatu yang wajar karena setiap orang berkepentingan dan menginginkan pendidikan yang baik bagi siswa, anak atau generasi penerus bangsa. Terlebih lagi, pendidikan merupakan tanggung jawab bersama antara keluarga, masyarakat dan pemerintah (Kartiwi, 2021). Oleh karena itu, pendidikan memiliki peran penting dalam mempengaruhi kemampuan seseorang (Maskur et al., 2020).

matematika menjadi salah satu mata pelajaran yang menyenangkan untuk siswa, tetapi kenyataannya masih banyak siswa yang kesulitan dalam mempelajari matematika (Utami \& Cahyono, 2020). Selama ini matematika menjadi sorotan dalam dunia pendidikan, terutama di sekolah-sekolah, Karena matematika ini membutuhkan tingkat pemahaman tersendiri dibandingkan dengan ilmuilmu lainnya. Matematika adalah ilmu yang sangat mendasar, tetapi pada kenyataanya, bagi sebagian siswa masih banyak siswa yang menganggap matematika sebagai pelajaran yang sulit, sehingga menyebabkan siswa mudah menyerah sebelum mempelajari matematika (Fauzy \& Nurfauziah, 2021), sehingga menimbulkan pemikiran negatif tentang matematika yang mengakibatkan hasil belajar matematika belum sesuai yang diharapkan. Hasil belajar peserta didik kurang memuaskan karena minat belajarnya masih rendah dan tingkat pemahaman konsep yang kurang (Kamelia et al., 2017), sehingga tidak memperhatikan saat guru menerangkan materi pelajaran yang kurang aktif dalam proses pembelajaran.

Dalam proses pembelajaran, guru tidak hanya berperan sebagai model/teladan bagi siswa yang diajarnya, tetapi juga sebagai pengelola pembelajaran (manager of learning) (Awaluddin et al., 2017). Guru harus memiliki kemampuan untuk memahami peserta didik dengan berbagai perbedaannya agar mampu membantu mereka dalam menghadapi kesulitan belajar (Abdullah, 2017). Dengan demikian, efektifitas proses pembelajaran terletak di pundak guru. Maka, Peranan guru sangat menentukan keberhasilan proses pembelajaran (Damanik, 2019).

Guru mempunyai peranan untuk menentukan suatu metode pembelajaran yang efektif dan mendukung siswa mendapatkan pembelajaran matemetika dan sekaligus memperoleh hasil belajar yang baik. Adanya sebuah paradigma yang berkembang di masyarakat bahwa proses belajar itu identik dengan buku dan menulis, secara tidak langsung telah mematikan kreativitas tenaga pendidik kita selama ini untuk mengeksplorasi sistem pengajaran yang dinamis dan efektif (Wulandari, 2017). Sistem pengajaran di Sekolah Menengah Pertama yang lebih menetapkan metode ceramah dalam kelas akan membosankan dan mononton. Sehingga peran aktif siswa 
Ensiklopedia, 01 (01), 2021 - 3

Lela Permanasari, Kenny Candra Pradana

dalam membangun pengetahuan sendiri belum terlalu besar. Padahal, siswa akan merasa puas dan nyaman jika metode pembelajaran yang dilakukan oleh guru sesuai dengan apa yang ia harapkan (Sholikhah \& Wahidah, 2021). Oleh karena itu, untuk menyikapi masalah tersebut, sebagai seorang guru harus mampu menciptakan metode dan suasana pembelajaran di dalam kelas yang sangat menyenangkan untuk siswa agar siswa tidak merasa adanya paksaan untuk dapat menemukan sendiri pengetahuannya (Nurgiansah \& Pringgowijoyo, 2020).

Berdasarkan hasil ulangan siswa kelas VII yang berjumlah 318 siswa, hanya $39 \%$ yang mencapai KKM yaitu sekitar 124 siswa, sedangkan 61\% siswa belum mencapai KKM yaitu sekitar 194 siswa. Keadaan ini dikarenakan interaksi sesama siswa untuk saling tukar pikiran sangatlah kurang dan aktivitas berdiskusi pun masih jarang dilakukan karena siswa hanya mendengarkan penjelasan guru, mencatat dan mengerjakan tugas saja. Hal ini diduga sebagai penyebab dari masih rendahnya hasil belajar siswa.

Salah satu model pembelajaran yang dapat memberikan kesempatan pada siswa untuk berperan aktif dalam setiap kegiatan pembelajaran yaitu Active Knowledge Sharing. Model Pembelajaran ini merupakan bagian dari pembelajaran aktif. Pembelajaran aktif adalah suatu proses pembelajaran dengan tujuan untuk memberdayakan siswa agar belajar dengan menggunakan berbagai cara/strategi secara aktif (Yamin, 2018). Model pembelajaran ini dapat menarik para peserta didik dengan segera kepada materi pelajaran dan membuat siswa merasa senang mengikuti pembelajaran karena suasana pembelajaran akan lebih hidup.

Berdasarkan uraian diatas, maka Tujuan dari penelitian ini adalah untuk mengetahui pengaruh model pembelajaran Active Knowledge Sharing terhadap hasil belajar matematika siswa kelas VII Semester Genap SMP Negeri 8 Bandar Lampung.

\section{METODE}

Metode yang digunakan adalah metode eksperimen, karena dengan sengaja melaksanakan pembelajaran pada dua kelas. Satu kelas sebagai kelas eksperimen yang menggunakan model pembelajaran Active Knowledge Sharing, dan satu kelas sebagai kelas kontrol yang menggunakan model pembelajaran konvensional. Selanjutnya di analisis bagaimana hasil belajar setelah kegiatan pembelajaran tersebut.

Dalam penelitian ini yang menjadi variabel X adalah "model pembelajaran Active Knowledge Sharing" dan yang menjadi variabel $\mathrm{Y}$ dalam penelitian ini adalah "Hasil belajar matematika". Pengukuran variabel dalam penelitian ini menggunakan tes. Perangkat tes yang dipergunakan dalam penelitian ini adalah tes uraian dengan jumlah soal adalah 10 soal.

Populasi dalam penelitian ini adalah semua siswa kelas VII Semester Genap SMP Negeri 8 Bandar Lampung. Penentuan sampel dalam penelitian ini menggunakan teknik Random Sampling. Setelah ditentukan, didapat kelas VII K sebanyak 21 orang sebagai kelas eksperimen dan kelas VII G sebanyak 23 orang sebagai kelas kontrol.

analisis data untuk menyimpulkan apakah penggunaan model pembelajaran Active Knowledge Sharing berpengaruh terhadap hasil belajar matematika, teknik analisisnya meliputi normalitas menggunakan uji Liliefors, yang dimaksudkan untuk menyimpulkan apakah sebaran sampel yang diamati berasal dari populasi yang berdistribusi normal atau tidak, uji homogenitas menggunakan uji Fisher, yang dimaksudkan untuk mengetahui apakah kedua kelompok mempunyai varians yang homogen, dan yang terakhir untuk menguji hipotesis menggunakan uji-t. 
Ensiklopedia, 01 (01), 2021 - 4

Lela Permanasari, Kenny Candra Pradana

\section{HASIL DAN PEMBAHASAN}

Setelah mengadakan proses pembelajaran pada kelas VII K sebagai kelas eksperimen yang berjumlah 21 siswa yang dengan menggunakan model pembelajaran Active Knowledge Sharing dan kelas VII G sebagai kelas kontrol berjumlah 23 siswa yang dalam proses pembelajarannya menggunakan model pembelajaran Konvensional, setelah itu penulis memberi tes pada kelas VII $\mathrm{K}$ dan VII G. Dalam pemberian tes penulis memberikan tes berbentuk essay sebanyak 10 soal dengan materi dan soal yang sama. Adapun hasil tes kelas eksperimen dan kelas kontrol selengkapnya dapat dilihat pada tabel berikut:

Tabel 1. Data Nilai Tes Siswa Kelas Kontrol dan kelas Eksperimen

\begin{tabular}{ccc} 
No. & $\begin{array}{c}\text { Kelas Kontrol } \\
\text { (VII G) }\end{array}$ & $\begin{array}{c}\text { Kelas Eksperimen } \\
\text { (VII K) }\end{array}$ \\
\hline 1. & 70 & 74 \\
2. & 40 & 82 \\
\hline
\end{tabular}

\begin{tabular}{rrr}
\hline 3. & 65 & 90 \\
4. & 52 & 94 \\
5. & 50 & 70 \\
6. & 40 & 64 \\
7. & 70 & 54 \\
8. & 45 & 70 \\
9. & 34 & 62 \\
10. & 48 & 90 \\
11. & 53 & 82 \\
12. & 65 & 70 \\
13. & 60 & 78 \\
14. & 63 & 45 \\
15. & 60 & 72 \\
16. & 80 & 70 \\
17. & 48 & 85 \\
18. & 70 & 62 \\
19. & 65 & 80 \\
20. & 40 & 76 \\
21. & 75 & 84 \\
22. & 50 & - \\
23. & 70 & - \\
$\overline{\boldsymbol{x}}$ & 55,46 & 73,79 \\
$\boldsymbol{S}$ & 13,29 & 12,48 \\
\hline
\end{tabular}

Sanjutnya, untuk menyimpulkan apakah kedua sampel yang diamati berdistribusi normal atau tidak maka dilakukan uji normalitas. Berikut hasilnya

Tabel 2. Analisis Uji Normalitas

\begin{tabular}{cccc}
\hline Kelompok & Statistic & df & Sig. \\
Eksperimen & 0,971 & 21 & 0,758 \\
Kontrol & 0,938 & 23 & 0,164 \\
\hline
\end{tabular}

Hipotesis yang diuji adalah:

Ho : Sampel berasal dari populasi yang berdistribusi normal, sig. $>\alpha$

H1 : Sampel tidak berasal dari populasi yang berdistribusi normal, sig $\leq$ $\alpha$.

Sehingga, berdasarkan tabel di atas diperoleh untuk kelas eksperimen nilai signifikansi $=0,758$, sehingga sig. $>\alpha$ dan untuk kelas kontrol nilai signifikansi = 0,164 , sehingga sig. $>\alpha$. Dengan demikian
Ho diterima (sampel berasal dari populasi yang berdistribusi normal).

Sesudah uji normalitas dan diketahui hasil penelitian yang mengindikasi bahwa kedua kelompok berdistribusi normal, Langkah berikutnya ialah melakukan pengujian homogenitas pada kedua kelompok guna menyimpulkan apakah kedua kelompok sampel memiliki varians homogen. Berikut hasilnya :

Tabel 3. Analisis Uji Homogenitas

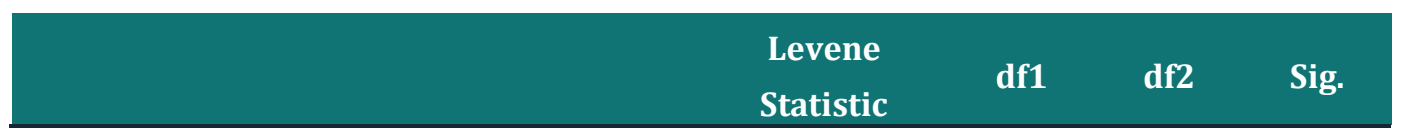


Ensiklopedia, 01 (01), 2021 - 5

Lela Permanasari, Kenny Candra Pradana

\begin{tabular}{llllrr}
\hline HASIL_BELAJAR & Based on Mean & .327 & 1 & 42 & .571 \\
_MATEMATIKA & Based on Median & .237 & 1 & 42 & .629 \\
& Based on Median and with & .237 & 1 & 40.802 & .629 \\
& $\begin{array}{l}\text { adjusted df } \\
\text { Based on trimmed mean }\end{array}$ & .321 & 1 & 42 & .574 \\
\hline
\end{tabular}

Pedoman Pengambilan keputusan dalam Uji Homogenitas :

Jika nilai Sig. Based on Mean > 0,05 maka varians data adalah Homogen, namun jika nilai Sig. basen on Mean $<0,05$ maka varians data adalah tidak homogen. Maka, berdasarkan table di atas dapat diketahui bahwa nilai Sig. Based on Mean adalah sebesar $0,571>0,05$. Sehingga dapat disimpulkan bahwa varians kelompok kelas eksperimen dan kelas kontrol adalah Homogen. Dengan demikian, Peneliti dapat menganalisis data hasil test kedua kelompok lewat Uji-t. Dasar penentuan uji T Test Independent berdasarkan nilai signifikansi (2-tailed) yang mengukur ada tidaknya perbedaan rata-rata pada subjek yang diujikan adalah

Nilai signifikansi (2-tailed) $>0.05$ menunjukkan tidak terdapat perbedaan rata-rata antar subjek penelitian. Namun jika nilai signifikansi (2-tailed) $<0.05$ menunjukkan adanya perbedaan rata-rata antar subjek penelitian. Berikut hasil uji-t:

Tabel 4. Analisis Uji Hipotesis

\begin{tabular}{|c|c|c|c|c|c|c|c|c|}
\hline \multirow[t]{2}{*}{$\mathbf{F}$} & \multirow[t]{2}{*}{ Sig. } & \multirow[t]{2}{*}{ t } & \multirow[t]{2}{*}{ df } & \multirow[t]{2}{*}{ Sig. (2-tailed) } & \multirow{2}{*}{$\begin{array}{c}\text { Mean } \\
\text { Difference }\end{array}$} & \multirow{2}{*}{$\begin{array}{l}\text { Std. Error } \\
\text { Difference }\end{array}$} & \multicolumn{2}{|c|}{$\begin{array}{c}95 \% \text { Confidence Interval } \\
\text { of the Difference }\end{array}$} \\
\hline & & & & & & & Lower & Upper \\
\hline \multirow{2}{*}{.327} & \multirow{2}{*}{.571} & -4.472 & 42 & .000 & -16.52174 & 3.69414 & -23.97682 & -9.06666 \\
\hline & & -4.471 & 41.593 & .000 & -16.52174 & 3.69512 & -23.98096 & -9.06252 \\
\hline
\end{tabular}

Tabel di atas menunjukkan nilai signifikansi 2 arah (t-tailed) $0.000<0.05$. Sehingga terdapat perbedaan skor point yang berarti antara kelompok kontrol dan eksperimen. Berdasarkan nilai deskriptifnya terbukti kelompok eksperimen dengan model pembelajaran Active Knowledge Sharing mendapat skor lebih tinggi.

Berdasarkan hasil penelitian dan analisis data, maka diperoleh gambaran secara umum tentang pengaruh model pembelajaran Active Knowledge Sharing terhadap hasil belajar matematika siswa kelas VII semester genap SMP Negeri 8 Bandar Lampung.

\section{KESIMPULAN DAN SARAN}

Berdasarkan hipotesis yang telah peneliti ajukan dan dilakukannya penelitian pada siswa kelas VII semester genap SMP Negeri 8 Bandar Lampung pada mata pelajaran matematika dapat disimpulkan penerapan model pembelajaran Active Knowledge Sharing berpengaruh signifikan hasil belajar matematika di kelas VII semester genap SMP Negeri 8 Bandar Lampung. model pembelajaran Active Knowledge Sharing) benar-benar menunjang proses pembelajaran, khususnya dalam kegiatan belajar matematika.

\section{REFERENSI}

Abdullah, R. (2017). Pembelajaran Dalam Perspektif Kreativitas Guru Dalam 
Ensiklopedia, 01 (01), 2021 - 6

Lela Permanasari, Kenny Candra Pradana

Pemanfaatan Media Pembelajaran. Lantanida Journal, 4(1), 35=49. https://doi.org/10.22373/lj.v4i1.18 66

Adelina Yuristia. (2018). Pendidikan Sebagai Transformasi Kebudayaan. Journal Ilmu Sosial Dan Budaya, 2(1), 1-13.

http://jurnal.uinsu.ac.id/index.php/ ijtimaiyah/article/view/5714

Awaluddin, Nasution, W. N., \& Zein, A. (2017). Analisis Sistem Pembelajaran Tilawah dan Tahfizh Alquran Di Sekolah Dasar SD Plus Jabal Rahmah Mulia Medan Sunggal. Edu Riligia, 1(2), 244-257.

Cahyono, H. (2015). Pola Pengembangan Pendidikan Karakter Siswa (Sebuah Studi Di SDN 1 Polorejo). Jurnal Dimensi Pendidikan Dan Pembelajran, 3(2), 5-12.

Damanik, R. (2019). Hubungan Kompetensi Guru Dengan Kinerja Guru. Jurnal Serunai Administrasi Pendidikan, $8(2)$. https://doi.org/10.37755/jsap.v8i2. 170

Fahmi, N., Sinaga, B., \& Rajagukguk, W. (2020). Analisis Kemampuan Metakognitif Siswa Dalam menyelesaikan Masalah Matematika di SMP Negeri 4 Bendahara Aceh Tamiang. Paradikma Jurnal Pendidikan Matematika, 13(2), 6872.

Fauzy, A., \& Nurfauziah, P. (2021). Kesulitan Pembelajaran Daring Matematika Pada Masa Pandemi COVID-19 di SMP Muslimin Cililin. Jurnal Cendekia: Jurnal Pendidikan Matematika, 5(1), 551-561. https://doi.org/10.31004/cendekia. v5i1.514

Kamelia, M., Ahmad, A., \& Novitasari, Y. (2017). Pengaruh Strategi Joyful Learning Dengan Teknik Mind Map Terhadap Hasil Belajar Kognitif Peserta Didik Kelas XI IPA SMA Negeri 6 Bandar Lampung. Biosfer:
Jurnal Tadris Biologi, 8(2), 132-157. https://doi.org/10.24042/biosf.v8i 2.2303

Kartiwi, D. P. (2021). Upaya Meningkatkan Aktivitas Dan Prestasi Belajar Melalui Penerapan Model Problem Based Learning Pada Siswa Kelas Xi Mipa 8 Sma Negeri 7 Denpasar Tahun Pelajaran 2020/2021. Widyadari, 22(1), 371-381. https://doi.org/10.5281/zenodo.46 61880

Maskur, R., Sumarno, Rahmawati, Y., Pradana, K., Syazali, M., Septian, A., \& Palupi, E. K. (2020). The Effectiveness of Problem Based Learning and Aptitude Treatment Interaction in Improving Mathematical Creative Thinking Skills on Curriculum 2013. European Journal of Educational Research, 9(1), 375-383. https://doi.org/10.12973/eujer.9.1.375

Nurgiansah, T. H., \& Pringgowijoyo, Y. (2020). Pelatihan Penggunaan Model Pembelajaran Jurisprudensial Pada Guru Di KB TK Surya Marta Yogyakarta. KUAT : Keuangan Umum Dan Akuntansi Terapan, 2(1), 52-57. https://doi.org/10.31092/kuat.v2i1 .661

Sholikhah, F. N., \& Wahidah, Z. (2021). Penggunaan Metode Pembelajaran Guru Biologi Di Pasuruan: Analisis Persepsi Siswa. ALVEOLI: Jurnal Pendidikan ..., 2(1), 16-29. https://alveoli.iainjember.ac.id/index.php/alv/article/ view/20

Sudarsana, I. K. (2016). Peningkatan Mutu Pendidikan Luar Sekolah Dalam Upayapembangunan Sumber Daya Manusia. Jurnal Penjaminan Mutu, 1(1), 1-14. https://doi.org/10.25078/jpm.v1i1. 34

Utami, Y. P., \& Cahyono, D. A. D. (2020). Study At Home: Analisis Kesulitan 
Ensiklopedia, 01 (01), 2021 - 7

Lela Permanasari, Kenny Candra Pradana

Belajar Matematika Pada Proses Pembelajaran Daring. Jurnal Ilmiah Matematika Realistik, 1(1), 20-26. https://doi.org/10.33365/jimr.v1i1.252

Wulandari, A. (2017). Pengembangan Media Pembelajaran Permainan Ular Tangga Berkartu Terhadap Kemampuan Menganalisis Pengaruh Gaya pada Siswa Kelas IV SDN Picisan Kabupaten Tulungagung Tahun Pelajaran 2016/2017. SimkiPedagogia, 1(5), 1-7.

Yamin, M. (2018). Penerapan Strategi Pembelajaran Active Knowledge Sharing Untuk Meningkatkan keterampilan Berkomunikasi dan Hasil Belajar IPA Siswa Kelas VIII SMP Negeri 2 Batukliang Tahun Pelajaran 2017/2018. JISIP, 2(3), 107-117.

http://dx.doi.org/10.1053/j.gastro. 2014.05.023\%0Ahttps://doi.org/10 .1016/j.gie.2018.04.013\%0Ahttp:// www.ncbi.nlm.nih.gov/pubmed/29 451164\%0Ahttp://www.pubmedce ntral.nih.gov/articlerender.fcgi?arti d=PMC5838726\%250Ahttp://dx.do i.org/10.1016/j.gie.2013.07.022\%2 50 